\title{
Expectativas y oportunidades en la función pública
}

\author{
Lluis Azemar Mallard \\ Secretaría de Administración y Función Pública \\ de la Generalitat de Cataluña \\ lazemar@gencat.net
}

\section{Resumen}

La función pública en Cataluña, la comunidad autónoma con menos empleo público, supone un 9\% de la población activa. El Libro Blanco de la Función Pública formula unas propuestas de actuación con el fin de promover la definición de un modelo propio. La aprobación del nuevo Estatuto de Autonomía de Cataluña (EAC) y del Estatuto Básico del Empleado Público (EBEP) modificará el marco normativo general y generará expectativas sobre las posibilidades de ampliación de autogobierno. El nuevo texto estatutario incluye los conceptos de «competencias exclusivas» $y$ «compartidas», introduciendo asi un nuevo parámetro para juzgar la constitucionalidad de la legislación estatal y autonómica.

Palabras clave: gestión pública, marco normativo, empleo público.

\begin{abstract}
The Public Function in Catalonia, the Spanish Autonomous Region with the least public employment, stands for $9 \%$ of the active population. The public function White Book draws several roads to action in order to promote the definition of a model of its own. The approval of both the new Catalan Statute of Autonomy (CSA or EAC) and the Basic Status of the Public Employee (BSPE or EBEP) will modify the general normative framework. Furthermore, it will generate new expectations about the possibilities of increasing self-government. The new statuary text includes the concepts of exclusive and shared competencies, introducing a new parameter to state the constitutionality of both the state and the regional legislation.
\end{abstract}

Key-words: public management, legal frameworkm public employment. 


\section{Concepto general de función pública y principales magnitudes del empleo público en Cataluña}

La función pública ${ }^{1}$ es el conjunto de personas que prestan servicios en la Administración de acuerdo con los principios de mérito y capacidad, mediante una relación profesional, retribuida y de carácter especial, por razón de los servicios públicos que se deben desarrollar, y regulada por la normativa administrativa o laboral. Es, por lo tanto, el factor humano de las organizaciones públicas y, como tal, uno de los recursos de que estas disponen para la gestión y la realización de los intereses públicos.

Asimismo, la función pública es un conjunto de subsistemas de gestión de esos recursos humanos (la selección del personal, la promoción y carrera, las incompatibilidades, los derechos y deberes, la salida del sistema, el régimen disciplinario, etc.) regidos por unos principios y unas normas específicas. Es pues, también, un sistema normativo que regula las relaciones orgánicas y las condiciones de trabajo en el ámbito del empleo público.

La relación de carácter estatutario o funcionarial se caracteriza por el hecho de que las condiciones de empleo no son establecidas bilateralmente por la Administración y el trabajador mediante una relación de naturaleza contractual, sino que se determinan mediante un conjunto de normas (leyes, reglamentos, resoluciones, etc.) que constituyen el denominado "estatuto funcionarial». La relación que vincula al funcionario con la Administración es, por lo tanto, de naturaleza estatutaria, no contractual. Desde el momento en que recibe el nombramiento y toma posesión del puesto de trabajo, al funcionario se le aplican un conjunto de normas que regulan los diferentes aspectos de sus condiciones de trabajo, su carrera profesional, sus derechos y deberes, sus responsabilidades, etc.

Con todo, hay que tener muy presente que en la Administración también hay personal vinculado bajo el régimen laboral, en concreto el personal interino y el personal eventual, que ejerce funciones de confianza o de asesoramiento especial.

Por lo que respecta a sus magnitudes, según datos del Libro Blanco de la Función Pública Catalana, el total del personal de las administraciones públicas catalanas era, a 1 de enero de 2005 , de 239.760 personas.

El mayor número de efectivos se concentra en la Administración de la Generalitat (60\%), seguida de la Administración local (32\%). Las universidades cuentan con cerca del $8 \%$ del personal y los entes parlamentarios, con el 0,2\%.

Sin embargo, a estas cifras hay que añadir el personal docente concertado $(24.000$ personas) y el personal que presta servicios en el ámbito de la sanidad bajo el régimen

1 A no ser que se indique lo contrario, los datos y las tablas que se incluyen en este trabajo se han extraído del Libro Blanco de la Función Pública Catalana. 
de concierto (56.000), según datos del propio Libro Blanco de la Función Pública Catalana.

A estos colectivos, por último, se deben sumar las 32.000 personas que prestan servicios a la Administración General del Estado en Cataluña.

En conclusión, el número de personas que desarrollan su trabajo en el servicio público en Cataluña se aproxima a 350.000, lo que representa un 9\% de la población activa.

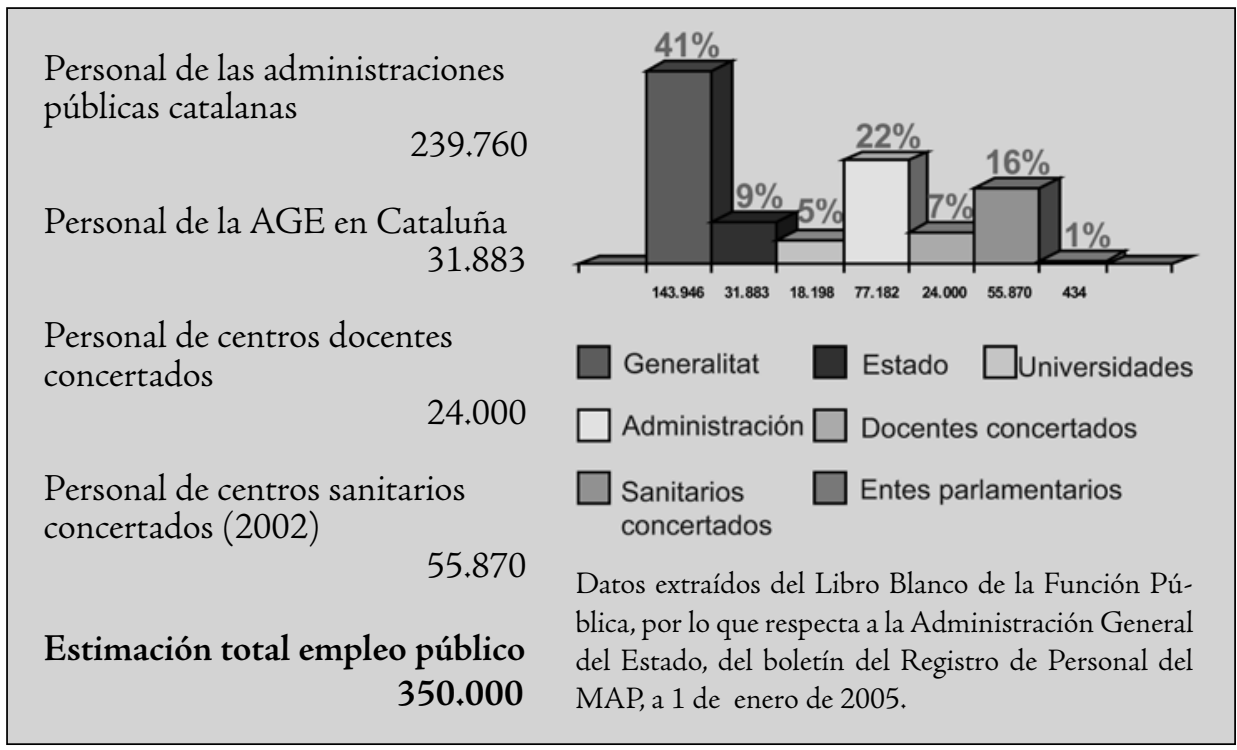

Esta cifra se debe comparar con la correspondiente a las administraciones públicas más próximas. En el cuadro siguiente, se observa que Cataluña, de forma clara y destacada, es la comunidad autónoma con menor número de empleados públicos sobre la población activa y también con menor número de empleados de la administración autonómica sobre la población activa.

\begin{tabular}{|l|c|c|c|c|}
\hline \multirow{2}{*}{$\begin{array}{c}\text { Comunidad } \\
\text { autónoma }\end{array}$} & \multicolumn{2}{|c|}{$\begin{array}{c}\text { Empleados públicos } \\
\text { en el territorio de la CA }\end{array}$} & \multicolumn{2}{c|}{$\begin{array}{c}\text { Empleados públicos } \\
\text { en la Administración de la CA }\end{array}$} \\
\cline { 2 - 5 } & $\begin{array}{c}\text { Por } \mathbf{1 0 0 0} \\
\text { habitantes }\end{array}$ & $\begin{array}{c}\text { Perc. sobre } \\
\text { población } \\
\text { activa }\end{array}$ & $\begin{array}{c}\text { Por } \mathbf{1 0 0 0} \\
\text { habitantes }\end{array}$ & $\begin{array}{c}\text { Perc, sobre } \\
\text { población activa }\end{array}$ \\
\hline Cataluña & 37 & $\mathbf{7 , 5 \%}$ & $\mathbf{1 9}$ & $\mathbf{3 , 9 \%}$ \\
\hline C. Valenciana & 44 & $9,3 \%$ & 25 & $5,2 \%$ \\
\hline Baleares & 46 & $9,2 \%$ & 22 & $4,4 \%$ \\
\hline País Vasco & 49 & $10,1 \%$ & 27 & $5,7 \%$ \\
\hline Galicia & 50 & $10,9 \%$ & 28 & $6,1 \%$ \\
\hline Navarra & 50 & $10,6 \%$ & 34 & $7,3 \%$ \\
\hline
\end{tabular}




\begin{tabular}{|c|c|c|c|c|}
\hline La Rioja & 51 & $10,9 \%$ & 30 & $6,5 \%$ \\
\hline Murcia & 52 & $11,2 \%$ & 29 & $6,3 \%$ \\
\hline Cantabria & 53 & $11,8 \%$ & 30 & $6,8 \%$ \\
\hline Asturias & 53 & $13,3 \%$ & 30 & $7,4 \%$ \\
\hline Andalucía & 57 & $13,2 \%$ & 30 & $6,9 \%$ \\
\hline Castilla-La Mancha & 61 & $14,2 \%$ & 32 & $7,4 \%$ \\
\hline Canarias & 62 & $13,1 \%$ & 28 & $6,1 \%$ \\
\hline Aragón & 65 & $14,2 \%$ & 30 & $6,7 \%$ \\
\hline Madrid & 66 & $13,2 \%$ & 25 & $5,0 \%$ \\
\hline Castilla y León & 66 & $15,0 \%$ & 33 & $7,7 \%$ \\
\hline Extremadura & 80 & $19,0 \%$ & 41 & $9,7 \%$ \\
\hline Ceuta & 119 & \multirow[b]{2}{*}{$32,2 \%$} & 20 & \multirow[b]{2}{*}{$4,8 \%$} \\
\hline Melilla & 127 & & 17 & \\
\hline Total & 54 & $11,6 \%$ & 27 & $5,8 \%$ \\
\hline
\end{tabular}

Fuente: Elaboración propia.

* No incluye personal del sector público empresarial de las comunidades autónomas, ni la prestación de servicios públicos por parte del sector privado.

Tabla elaborada a partir de los datos siguientes:

(1) Cifras de población a 1 de enero de 2005: datos provisionales del Instituto Nacional de Estadística (www.ine.es).

(2) Encuesta de población activa del cuarto trimestre de 2004, publicada por el Instituto Nacional de Estadística (www.ine.es).

(3) Datos del Ministerio de Administraciones Públicas a 1 de enero de 2005 (www.map.es). Además del personal propio de cada comunidad Autónoma, incluye el personal de la Administración del Estado, de la Administración local y de las universidades.

Al sumar el personal de los centros docentes concertados y el personal que presta servicios en la sanidad privada concertada, las proporciones varían, pero Cataluña continúa siendo una comunidad autónoma con un bajo índice de empleo público sobre la población activa, como se puede constatar en la siguiente tabla.

\begin{tabular}{|l|c|c|c|c|}
\hline \multirow{2}{*}{$\begin{array}{c}\text { Comunidad } \\
\text { autónoma }\end{array}$} & \multicolumn{2}{|c|}{$\begin{array}{c}\text { Empleados públicos } \\
\text { en el territorio de la CA }\end{array}$} & \multicolumn{2}{c|}{$\begin{array}{c}\text { Empleados públicos } \\
\text { en la Administración de la CA }\end{array}$} \\
\cline { 2 - 5 } & $\begin{array}{c}\text { Por } \mathbf{1 0 0 0} \\
\text { habitantes }\end{array}$ & $\begin{array}{c}\text { Perc. sobre } \\
\text { población activa }\end{array}$ & $\begin{array}{c}\text { Por } \mathbf{1 0 0 0} \\
\text { habitantes }\end{array}$ & $\begin{array}{c}\text { Perc. sobre } \\
\text { población } \\
\text { activa }\end{array}$ \\
\hline & 44 & $\mathbf{9 , 3 \%}$ & $\mathbf{1 9}$ & $3, \mathbf{9 \%}$ \\
\hline C. Valenciana & 46 & $9,2 \%$ & 22 & $5,2 \%$ \\
\hline Baleares & 49 & $10,1 \%$ & 27 & $4,4 \%$ \\
\hline País Vasco & $\mathbf{4 8 , 6 5}$ & $\mathbf{9 , 4 8 \%}$ & & $5,7 \%$ \\
\hline Cataluña & 50 & $10,9 \%$ & 28 & $6,1 \%$ \\
\hline Galicia & & \multicolumn{3}{|c}{} \\
\hline
\end{tabular}




\begin{tabular}{|c|c|c|c|c|}
\hline Navarra & 50 & $10,6 \%$ & 34 & $7,3 \%$ \\
\hline La Rioja & 51 & $10,9 \%$ & 30 & $6,5 \%$ \\
\hline Murcia & 52 & $11,2 \%$ & 29 & $6,3 \%$ \\
\hline Cantabria & 53 & $11,8 \%$ & 30 & $6,8 \%$ \\
\hline Asturias & 53 & $13,3 \%$ & 30 & $7,4 \%$ \\
\hline Andalucía & 57 & $13,2 \%$ & 30 & $6,9 \%$ \\
\hline Castilla-La Mancha & 61 & $14,2 \%$ & 32 & $7,4 \%$ \\
\hline Canarias & 62 & $13,1 \%$ & 28 & $6,1 \%$ \\
\hline Aragón & 65 & $14,2 \%$ & 30 & $6,7 \%$ \\
\hline Madrid & 66 & $13,2 \%$ & 25 & $5,0 \%$ \\
\hline Castilla y León & 66 & $15,0 \%$ & 33 & $7,7 \%$ \\
\hline Extremadura & 80 & $19,0 \%$ & 41 & $9,7 \%$ \\
\hline Ceuta & 119 & \multirow[b]{2}{*}{$32,2 \%$} & 20 & \multirow[b]{2}{*}{$4,8 \%$} \\
\hline Melilla & 127 & & 17 & \\
\hline Total & 54 & $11,6 \%$ & 27 & $5,8 \%$ \\
\hline
\end{tabular}

Fuente: Elaboración propia.

* No incluye personal del sector público empresarial de las comunidades autónomas, ni la prestación de servicios públicos por parte del sector privado.

Tabla elaborada a partir de los siguientes datos:

(1) Cifras de población a 1 de enero de 2005: datos provisionales del Instituto Nacional de Estadística (www.ine.es).

(2) Encuesta de población activa del cuarto trimestre de 2004, publicada por el Instituto Nacional de Estadística (www.ine.es).

(3) Datos del Ministerio de Administraciones Públicas a 1 de enero de 2005 (www.map.es). Además del personal propio de cada comunidad Autónoma, incluye el personal de la Administración del Estado, de la Administración local y de las universidades.

Visto desde otra perspectiva, los datos se confirman. El gráfico siguiente muestra el número de habitantes por empleado público en España, por comunidades autónomas, según datos de 2006.

Las dos cifras relativas a Cataluña expresan el cálculo sin tener en cuenta el personal del sector privado concertado y teniéndolo en cuenta, respectivamente.

Finalmente, hay que tener en cuenta también que el peso y las dimensiones del empleo público en Cataluña tienen reflejo en la importancia relativa de su coste en términos presupuestarios. En este sentido, es importante subrayar que el coste del empleo público representa un gasto muy considerable en la gestión de los presupuestos de las administraciones públicas catalanas, que se puede estimar — según datos del Libro Blanco de la Función Pública, referidos a los presupuestos iniciales para 2003 - en un $34 \%$ sobre el total de gastos corrientes. 


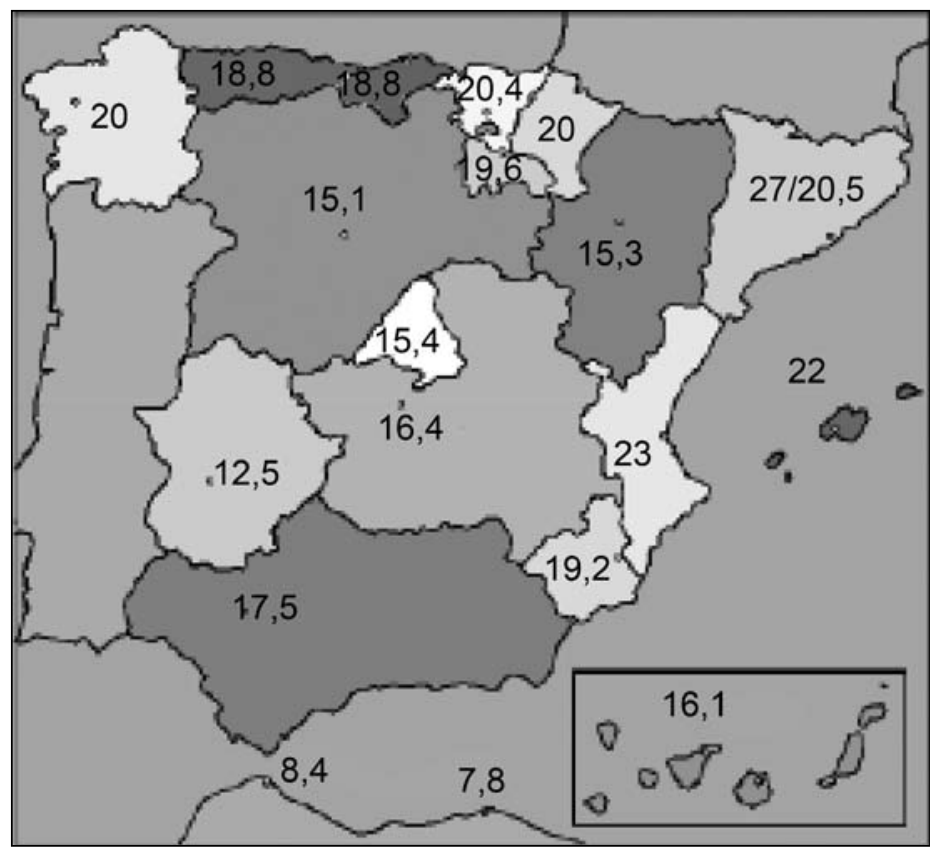

España: 18,5

Francia: 12

Alemania: 25

Fuente: Basado en datos publicados en el diario Expansión y de elaboración propia.

\section{El Libro Blanco de la Función Pública Catalana: diagnosis y propuestas}

En sesión informativa de la Comisión de Organización y Administración de la Generalitat y Gobierno Local del Parlamento de Cataluña, de 12 de febrero de 2004, el conseller de Gobernación y Administraciones Públicas adquirió públicamente el compromiso de elaborar un libro blanco sobre la función pública catalana, con el objetivo de analizar su situación desde las diversas administraciones implicadas y con la participación de todos los agentes sociales, para evaluar si responde adecuadamente a la realización de los intereses públicos de los ciudadanos de Cataluña y formular unos objetivos y unas propuestas de actuación en forma de recomendaciones con el fin de promover la definición de un modelo propio de función pública.

El ámbito del estudio abarcó las diferentes administraciones públicas catalanas, es decir, las que se incluyen en el cuadro siguiente: 


\begin{tabular}{|c|c|c|c|}
\hline $\begin{array}{c}\text { Administración de la } \\
\text { Generalitat }\end{array}$ & Administración local & Universidades & $\begin{array}{c}\text { Entes } \\
\text { parlamentarios }\end{array}$ \\
\hline $\begin{array}{l}\text { + Departamentos de la } \\
\text { Administración de la } \\
\text { Generalitat (16) y sus } \\
\text { entidades autónomas } \\
\text { de carácter administra- } \\
\text { tivo (24) } \\
\text { + Entidades autó- } \\
\text { nomas de carácter } \\
\text { comercial, industrial y } \\
\text { financiero (4) } \\
\text { + Entidades gestoras } \\
\text { de la Seguridad Social } \\
\text { (2) } \\
\text { + Servicio Catalán de } \\
\text { la Salud } \\
\text { + Comisión Jurídica } \\
\text { Asesora }\end{array}$ & $\begin{array}{l}\text { + Ayuntamientos (946) } \\
+ \text { Consejos comarcales } \\
(41) \\
+ \text { Diputaciones (4) } \\
\text { + Entidades municipales } \\
\text { descentralizadas (58) } \\
\text { + Mancomunidades } \\
\text { (49) } \\
\text { + Entidades metropoli- } \\
\text { tanas }(2) \\
+ \text { Entes de gestión local: } \\
\text { - Empresas públicas } \\
\text { (200) } \\
\text { - Organismos } \\
\text { autónomos (460) }\end{array}$ & $\begin{array}{l}\text { + Universidad } \\
\text { de Barcelona } \\
+ \text { Universidad } \\
\text { Autónoma de } \\
\text { Barcelona } \\
\text { + Universidad } \\
\text { Politécnica de } \\
\text { Cataluña } \\
\text { + Universidad } \\
\text { Pompeu Fabra } \\
\text { + Universidad } \\
\text { de Lleida } \\
\text { + Universidad de } \\
\text { Girona } \\
\text { + Universidad } \\
\text { Rovira i Virgili }\end{array}$ & $\begin{array}{l}\text { + Parlamento } \\
\text { de Cataluña } \\
+ \text { Síndic de } \\
\text { Greuges } \\
+ \text { Sindicatura } \\
\text { de Cuentas } \\
+ \text { Consejo del } \\
\text { Audiovisual de } \\
\text { Cataluña } \\
+ \text { Consejo } \\
\text { Consultivo }\end{array}$ \\
\hline
\end{tabular}

Desde el punto de vista operativo, el Libro Blanco se planteó de acuerdo con las siguientes actuaciones:

1. La creación de un grupo de trabajo.

2. La creación de una base de datos de función pública de todas las administraciones públicas catalanas.

3. La organización de debates sobre la función pública con representación de diversos posicionamientos doctrinales, políticos y sociales.

4. Una serie de consultas a varios colectivos afectados o que son parte interesada en la materia.

5. Un sondeo de opinión a la ciudadanía.

Fruto de este planteamiento, el Libro Blanco tiene la siguiente estructura: a) Introducción; $b$ ) Desarrollo de propuestas; $c$ ) Datos estadísticos de personas; $d$ ) Ponencias de los expertos invitados y e) Sondeo de opinión a la ciudadanía. 


\subsection{Los datos estadísticos}

El total del personal de las administraciones públicas catalanas era, a 1 de enero de 2005, de 239.760 personas.

\begin{tabular}{|llr|}
\hline Administración Pública & & Total \\
\hline Administración de la Generalitat & & 143.946 \\
\hline & Departamentos & 95.148 \\
\hline & Entidades autónomas & 38.050 \\
\hline & Sector público empresarial & 10.748 \\
\hline Administración local & & 77.182 \\
\hline & Entes locales & 53.926 \\
\hline & Entes de gestión & 23.256 \\
\hline Universidades & & 18.198 \\
\hline Entes parlamentarios & & 434 \\
\hline & & 239.760 \\
\hline
\end{tabular}

Por lo que respecta al personal de la Administración de la Generalitat, más de dos terceras partes (67\%) son empleados públicos de los departamentos de Educación y de Salud. En cuanto a la Administración local, el 60\% son empleados públicos de municipios de más de 20.000 habitantes.

El grueso del personal de las administraciones públicas se encuentra en colectivos de cualificación profesional especializada, servicios prestacionales o finalistas (docencia, salud, policía, Administración de Justicia, servicios penitenciarios, bomberos, agentes rurales), que representan el $57 \%$ de todo el personal. Entre estos colectivos, los más importantes son los correspondientes a la docencia (28\% del total) y la salud (15\% del total).

\begin{tabular}{|l|l|l|l|l|l|}
\hline Colectivo & Generalitat & Local & Universidades & Entes parl. & Total \\
\hline Directivo & 451 & 458 & 47 & 29 & 983 \\
\hline Eventual & 189 & 823 & $\star$ & 34 & 1.046 \\
\hline Administración y servicios** & 25.148 & 58.857 & 6.585 & 371 & 90.961 \\
\hline Docente & 52.936 & 3.618 & 11.586 & & 68.120 \\
\hline Salud & 33.079 & 2.879 & & & 35.958 \\
\hline Policía & 10.782 & 9.912 & & & 20.694 \\
\hline Bomberos & 2.228 & 637 & & & 2.865 \\
\hline Otros & & & & & 19.133 \\
\hline Administración de Justicia & 5.987 & & & & \\
\hline Servicios penitenciarios & 2.290 & & & & \\
\hline Agentes rurales & 397 & & & & \\
\hline Sector público empresarial & 10.459 & & & $\mathbf{4 3 4}$ & $\mathbf{2 3 9 . 7 6 0}$ \\
\hline Total & $\mathbf{1 4 3 . 9 4 6}$ & $\mathbf{7 7 . 1 8 2}$ & $\mathbf{1 8 . 1 9 8}$ & & \\
\hline
\end{tabular}


* No se dispone de los datos correspondientes al personal eventual.

** Incluye el personal de administración general y especial y el personal laboral (excepto el docente, el de la salud y el contratado de alta dirección) de la Administración de la Generalitat y de la Administración local, y el personal de administración y servicios de los entes parlamentarios y de las universidades.

SAFP; Gabinete de Apoyo Técnico y Estudios.

Fuente: GIP/SIP, BOLB.

Respecto a la vinculación, el $71 \%$ del personal de las administraciones públicas catalanas está sujeto al régimen funcionarial, mientras que el $28 \%$ es laboral. Por administraciones, es en la Administración de la Generalitat donde hay un porcentaje más elevado de personal funcionario (85\%), mientras que en la Administración local, por el contrario, se encuentra el porcentaje más alto de personal laboral.

En cuanto a la estabilidad en las administraciones públicas catalanas (personal funcionario y personal laboral indefinido), se puede afirmar que es alta (78\%); en este sentido, destaca en particular el personal de la Administración local (82\%). Por el contrario, es en las universidades donde hay un menor índice de estabilidad, con un 33\% de personal interino y laboral temporal.

\begin{tabular}{|c|c|c|c|c|c|c|c|}
\hline & \multirow[b]{2}{*}{ Directivo } & \multirow[b]{2}{*}{ Eventual } & \multicolumn{2}{|l|}{ Funcionario } & \multicolumn{2}{|l|}{ Laboral } & \multirow[b]{2}{*}{ Total } \\
\hline & & & \begin{tabular}{|l|} 
Funcionario/ \\
Estatutario
\end{tabular} & Interino* & Indefinido & Temporal & \\
\hline $\begin{array}{l}\text { Administración de } \\
\text { la Generalitat }\end{array}$ & 451 & \begin{tabular}{|l|}
189 \\
\end{tabular} & 95.202 & 26.556 & 15.053 & 6.495 & 143.946 \\
\hline $\begin{array}{l}\text { Administración } \\
\text { local }\end{array}$ & 456 & 823 & 30.410 & 4.879 & 32.052 & 8.562 & 77.182 \\
\hline Universidades & 47 & $* *$ & 9.844 & 4.184 & 2.354 & 1.789 & 18.198 \\
\hline $\begin{array}{l}\text { Entes } \\
\text { parlamentarios }\end{array}$ & 29 & 34 & 210 & 92 & 46 & 23 & 434 \\
\hline Subtotal & & & 135.666 & 35.711 & 49.505 & 16.949 & \\
\hline Total & 983 & 1.046 & 171.377 & & 66.354 & & 239.760 \\
\hline
\end{tabular}

SAFP; Gabinete de Apoyo Técnico y Estudios.

Fuente: GIP/ SIP, BOLB.

Por grupo de titulación, en el conjunto de las administraciones públicas, el porcentaje más alto corresponde al personal del grupo B (27\%), seguido del grupo A (25\%) y del grupo D (22\%). En la Administración de la Generalitat, el predominio del grupo B (35\%) se explica por la importancia del personal de los colectivos vinculados al ámbito de la docencia y de la salud (personal de enfermería). En cambio, en la Administración local, el 38\% del grupo D se explica por el grueso del personal que presta servicios en el ámbito de la política de seguridad ciudadana (policía local). 


\begin{tabular}{|l|l|l|l|l|l|}
\hline & $\begin{array}{l}\text { Administración } \\
\text { de la Generalitat }\end{array}$ & $\begin{array}{c}\text { Administración } \\
\text { local }\end{array}$ & Universidades* & $\begin{array}{c}\text { Entes } \\
\text { parlamentarios }\end{array}$ & Total \\
\hline Grupo A & 40.624 & 8.774 & 11.521 & 116 & 61.035 \\
\hline Grupo B & 50.897 & 11.032 & 2.044 & 67 & 64.040 \\
\hline Grupo C & 23.177 & 15.626 & 2.776 & 130 & 41.709 \\
\hline Grupo D & 22.215 & 29.567 & 1.650 & 84 & 53.516 \\
\hline Grupo E & 6.643 & 11.639 & 160 & 6 & 18.448 \\
\hline Otros & 390 & 544 & 47 & 31 & 1.012 \\
\hline Total & 143.946 & 77.182 & 18.198 & 434 & 239.760 \\
\hline
\end{tabular}

* Los grupos I, II, III, IV y V se han asimilado a los grupos A, B, C D y E, respectivamente. SAFP; Gabinete de Apoyo Técnico y Estudios.

Fuente: GIP/ SIP, BOLB.

Por lo que respecta al género, el 55\% del personal de las administraciones públicas catalanas son mujeres. Es en la Administración de la Generalitat donde su número es más elevado (62\%), mientras que los menores porcentajes se dan en las universidades (42\%) y en la Administración local (44\%). Los colectivos donde trabajan más mujeres son el personal de salud (70\%) y el personal docente (63\%), mientras que los menores porcentajes se dan en los cuerpos de policía (15\%) y bomberos (inferior al 1\%).

\section{Distribución de mujeres y hombres en las administraciones públicas de Cataluña}

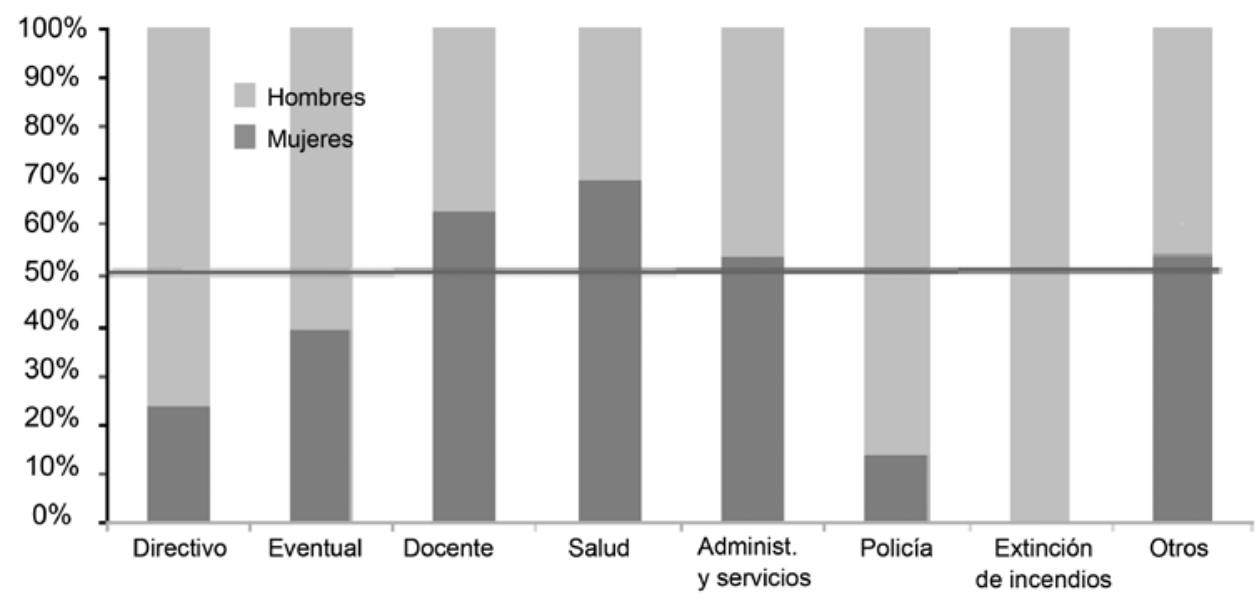

Con respecto a la edad, la franja mayoritaria es la comprendida entre los 31 y los 45 años. El personal más joven, de entre 18 y 30 años, es más numeroso en los entes parlamentarios (15\%), franja de edad donde también es destacable el porcentaje de mujeres $(69 \%)$. 


\begin{tabular}{|l|l|l|l|l|}
\hline & $\begin{array}{l}\text { Administración } \\
\text { de la Generalitat }\end{array}$ & Ayuntamientos* & Universidades & $\begin{array}{c}\text { Entes } \\
\text { parlamentarios }\end{array}$ \\
\hline $18-30$ & $11,0 \%$ & $9,4 \%$ & $9,3 \%$ & $15,3 \%$ \\
\hline $31-45$ & $47,8 \%$ & $45,8 \%$ & $49,4 \%$ & $53,6 \%$ \\
\hline $46-60$ & $38,1 \%$ & $39,0 \%$ & $35,4 \%$ & $26,9 \%$ \\
\hline $61-64$ & $2,7 \%$ & $5,3 \%$ & $4,0 \%$ & $3,3 \%$ \\
\hline$\geq 65$ & $0,4 \%$ & $0,5 \%$ & $1,9 \%$ & $0,9 \%$ \\
\hline & & & & \\
\hline
\end{tabular}

* Datos obtenidos de un muestreo de 280 ayuntamientos, que representan 19.942 efectivos (con un error del $4,94 \%)$.

En cuanto a la distribución territorial, la mayor parte del personal de las administraciones catalanas se concentra en el ámbito metropolitano, donde trabaja el 66\% de los empleados públicos. Este porcentaje se corresponde con la densidad de estas comarcas (Barcelonès, Baix Llobregat, Maresme, Vallès Occidental, Vallès Oriental, Garraf y Alt Penedès), donde vive el $69 \%$ de la población de Cataluña.

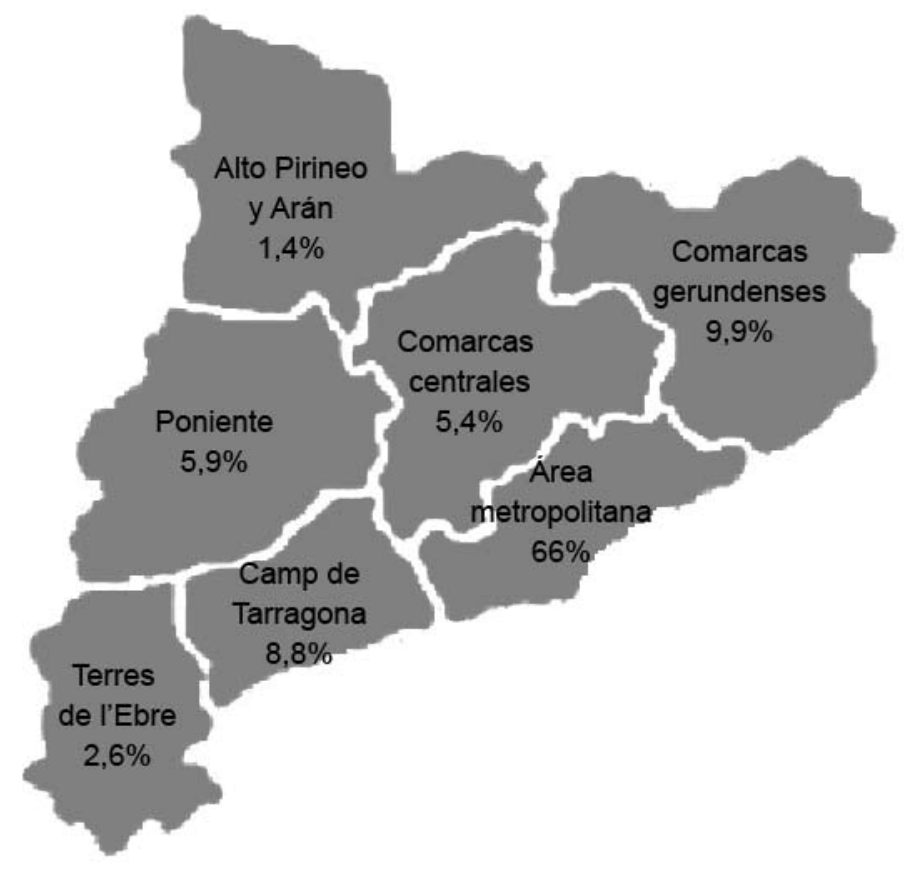

Así pues, a la vista de los datos estadísticos presentados, si tuviéramos que definir un perfil del empleado en el sector público, este tendría las siguientes características: 


$\begin{array}{lll}\text { Género } & \text { Mujer } & (55 \%) \\ \text { Edad } & 31-45 & (48 \%) \\ \text { Forma de empleo } & \text { Estable } & (78 \%) \\ \text { Vinculación } & \text { Funcionaria } & (71 \%) \\ \text { Titulación } & \text { Diplomada } & (27 \%) \\ \text { Colectivo } & \text { Docente } & (28 \%) \\ \text { Territorio } & \text { Metropolitano } & (66 \%)\end{array}$

\subsection{El Libro Blanco de la Función Pública Catalana: diagnosis y propuestas}

Las propuestas y recomendaciones del Libro Blanco de la Función Pública Catalana se articulan esencialmente en torno a tres grandes ejes:

1) Una función pública catalana

2) Una función pública profesional al servicio del ciudadano

3) Una función pública gestionada con eficacia

El primer eje —una función pública catalana-, a su vez, se basa en tres líneas de actuación:

1.1 La definición y regulación de un espacio único de función pública catalana (es decir, un nuevo marco regulador):

- Cataluña debe disponer de competencia exclusiva sobre todo el personal del sector público del país.

- Es preciso elaborar una ley marco del empleo público de Cataluña.

- Es preciso elaborar un estatuto único y específico para la dirección pública de Cataluña.

1.2 El establecimiento de nuevos sistemas de estructuración flexibles y adaptados a las necesidades (es decir, un nuevo modelo de gestión de los recursos humanos):

- El dimensionamiento del empleo público debe ser sostenible.

- Es preciso asumir la convivencia de diferentes regímenes de vinculación dentro de la función pública.

- Es preciso estructurar la función pública de forma más simple y flexible.

- La utilización del régimen de la eventualidad (puestos de confianza y asesoramiento especial) debe ser congruente y homogénea en todas las administraciones públicas. 
1.3 La configuración de instituciones y herramientas de planificación y gestión integradas y coordinadas de políticas de recursos humanos, que se concreta en las siguientes propuestas:

- Desarrollar un modelo útil de relación de puestos de trabajo, un único concepto de plantilla, una sola oferta de empleo y una nueva organización de los cuerpos.

- Generalizar los registros de personal y el uso intensivo de las tecnologías de la información en la gestión de los recursos humanos.

- Realizar convocatorias conjuntas de procesos selectivos.

- Universalizar los sistemas de provisión y establecer el concurso general permanente.

- Plantear un modelo de carrera profesional común.

- Simplificar la negociación de las condiciones de trabajo.

- Establecer un sistema de garantías extrajudicial.

- Crear el Consejo Catalán del Empleo Público y el Observatorio del Empleo Público de Cataluña.

El segundo eje — una función pública profesional— se fundamenta también en tres grandes líneas de actuación y una serie de propuestas asociadas. Son las siguientes:

2.1 Fomento de los valores del servicio público y el comportamiento ético para prestigiar la función pública del país:

- Es preciso implantar una gestión de la infraestructura de la ética.

2.2 Introducción de la evaluación del desarrollo como herramienta imprescindible para legitimar el trabajo público:

- Mediante la potenciación de la evaluación del desarrollo.

- Empleando un modelo como el de la gestión de los recursos humanos por competencias.

2.3 Simplificación de la gestión de los recursos humanos en beneficio de una mayor transparencia y de la mejora de las garantías para el ciudadano:

- Empleando procedimientos de selección comunes para todas las administraciones públicas.

Finalmente, el tercer eje — una función pública gestionada con eficacia- se fundamenta en las siguientes líneas de actuación:

3.1 Mejora de los sistemas de selección de personal: 
- Evaluación a partir de los perfiles profesionales de los puestos y de las competencias genéricas.

- Establecimiento de dos fases de oposición y de un periodo de prueba.

3.2 Reforma de los sistemas de provisión de puestos de trabajo:

- Establecimiento de un sistema de concurso general permanente.

- Nuevos criterios para la valoración de los candidatos.

- Determinación de límites temporales en relación con la estabilidad en el puesto de trabajo y, en particular, en los puestos de mando.

- Universalización de la carrera profesional

3.3 Reorganización del sistema retributivo:

- Se debe garantizar la retención de los mejores y hacer atractiva la incorporación al servicio público como opción profesional.

- Las recompensas por el simple transcurso del tiempo deben desaparecer.

- La productividad debe ir asociada a una verdadera evaluación del desarrollo.

3.4 Institucionalización de la dirección pública:

- Definición de los contornos de la dirección pública.

- Garantía de una selección basada en la competencia.

- Mandato de duración determinada, que debe concretarse en un marco formal mediante el acuerdo de gestión.

- Sistema retributivo ajustado a los resultados.

\subsection{Sondeo de opinión sobre la imagen de los empleados públicos}

En relación con la confianza en los diferentes colectivos de trabajadores, el sondeo muestra los resultados siguientes: 


\section{Confianza de la población en diversos colectivos de las administraciones públicas}

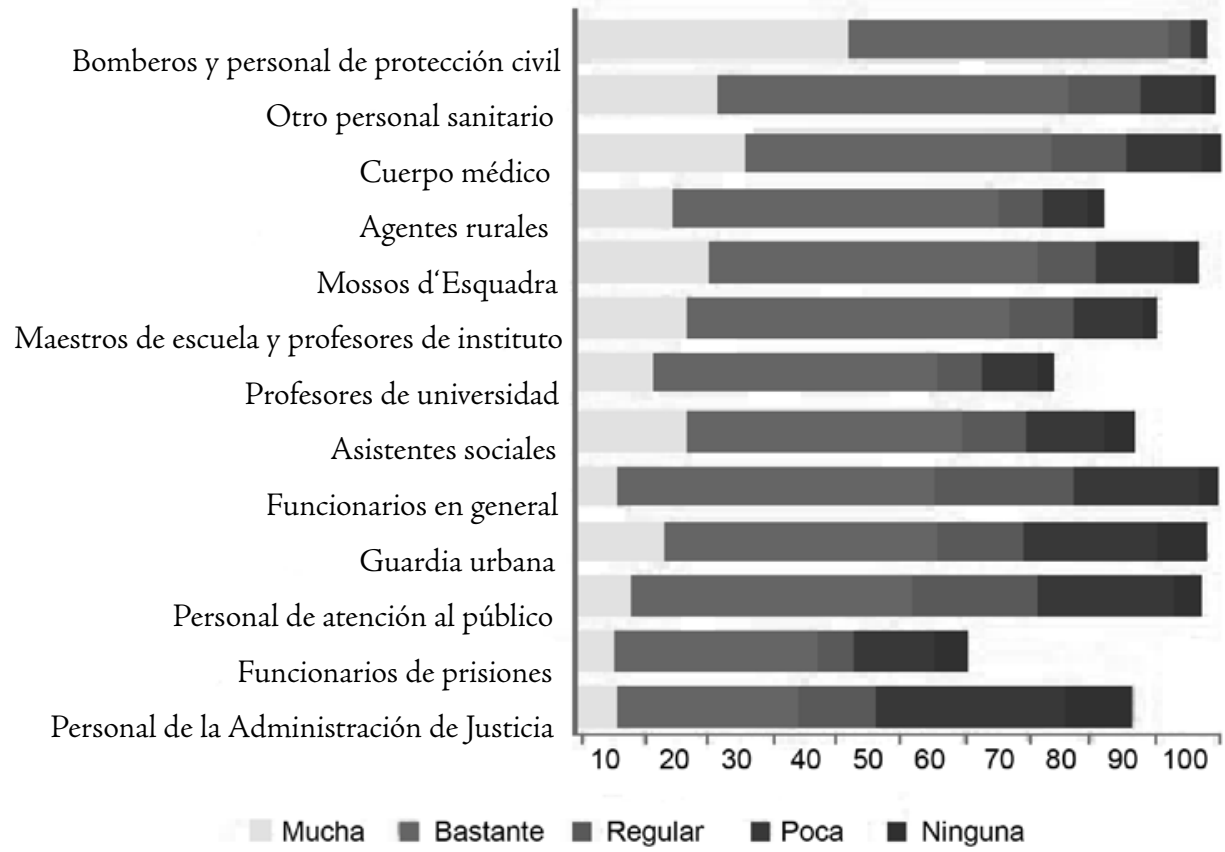

De este sondeo se desprende que la valoración de los ciudadanos está muy vinculada al estereotipo del típico funcionario de ventanilla. La mayoría de los encuestados manifiesta tener mucha $(5,8 \%)$ o bastante $(50,1 \%)$ confianza en los funcionarios en general $y$, en particular, en los bomberos (92,5\%). También los Mossos d'Esquadra gozan de notable confianza (71,2\%); en cambio, en el caso de la Guardia urbana, ese porcentaje desciende hasta el 55,9\%. Los trabajadores de los servicios de salud obtienen valoraciones muy similares y satisfactorias. Los maestros de escuela y el profesorado de instituto y de universidad tienen una posición intermedia, mientras que el personal de la Administración de Justicia es el único colectivo de todos los incluidos en la encuesta que recibe un número más elevado de valoraciones negativas (40\%) que positivas $(34,1 \%)$.

En relación con la percepción ciudadana de la calidad de los funcionarios y los trabajadores públicos, el sondeo arroja los siguientes resultados: 


\section{Calidad de los trabajadores públicos}

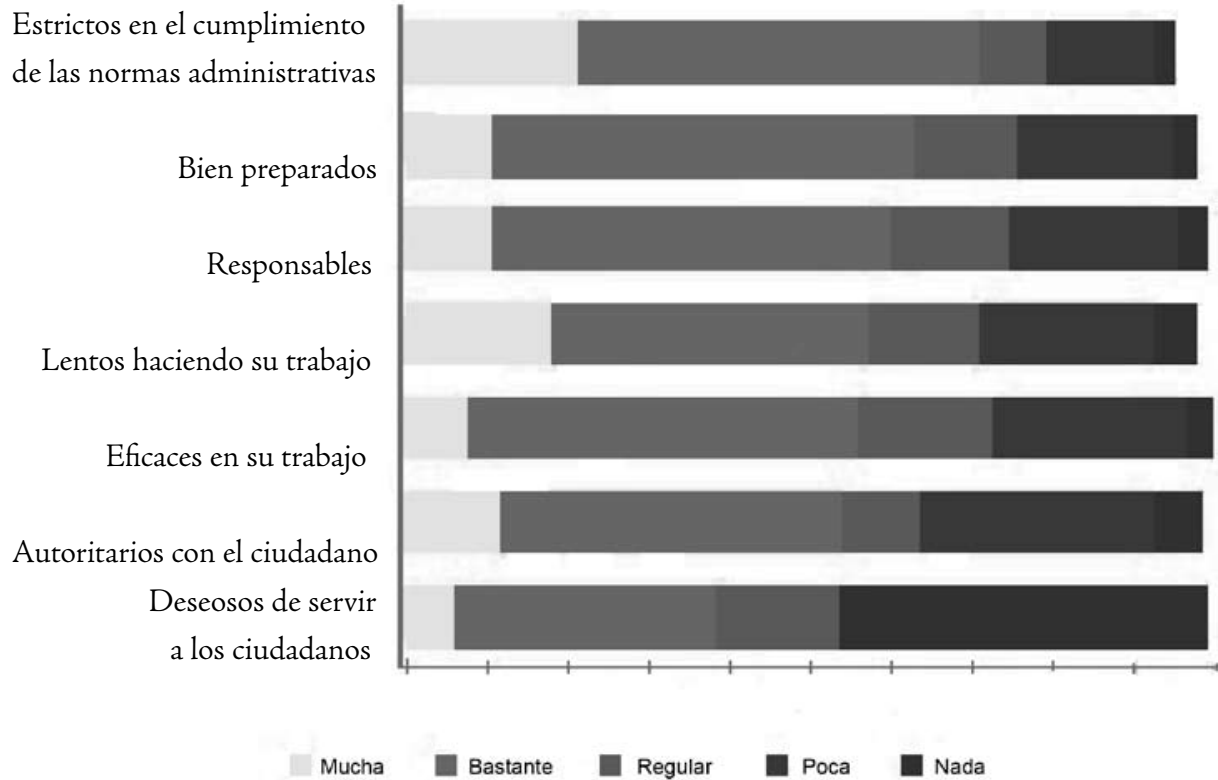

De la gráfica anterior se desprende que la mayoría de los encuestados (casi el 70\%) considera a los funcionarios y trabajadores públicos (muy o bastante) estrictos en el cumplimiento de las normas administrativas, pero también bien preparados $(61,7 \%)$, responsables $(59,2 \%)$, lentos $(56,2 \%)$ y autoritarios $(53,3 \%)$, aunque eficaces a la hora de hacer su trabajo $(54,8 \%)$.

En conjunto, estas opiniones transmiten la imagen de un funcionario competente y capaz, que hace bien y honradamente su trabajo, pero que falla en el trato personal con el ciudadano, porque se muestra distante e inflexible.

El sondeo también pregunta a los encuestados por su opinión acerca de los funcionarios, en comparación con los trabajadores de las grandes empresas del sector privado. Las respuestas quedan reflejadas en la siguiente gráfica:

Preparados para hacer su trabajo Satisfechos con su trabajo Motivados para hacer bien su trabajo

Preocupados por dar un servicio de calidad

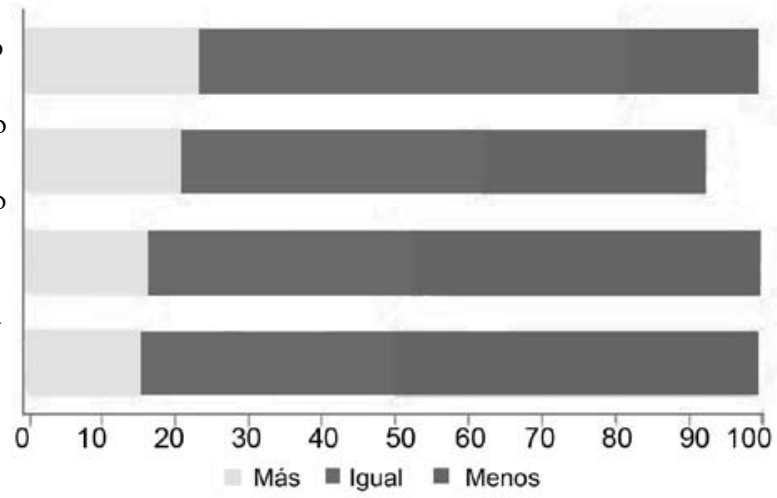


Las respuestas apuntan que los trabajadores del sector público están tanto o más preparados que los trabajadores del sector privado para hacer bien su trabajo (según la opinión del $78,4 \%$ ), pero claramente menos preocupados por la calidad del servicio que ofrecen, menos motivados y poco satisfechos con lo que hacen.

Seguidamente, se formulan una serie de afirmaciones de carácter general sobre el régimen funcionarial, respecto de las cuales se pide a los encuestados que indiquen su grado de acuerdo.

Los funcionarios deben tener garantizado su puesto de trabajo para no depender de los cambios políticos al frente de la Administración

En términos generales, los funcionarios están bien pagados

Los funcionarios disponen de las herramientas necesarias para prestar de forma correcta los servicios que tienen asignados

A menudo, el trato que los funcionarios dan al ciudadano responde a las doctrinas de sus superiores políticos

El sistema de selección de trabajadores públicos es justo y garantiza la igualdad de oportunidades

Hay más funcionarios de los que hacen falta

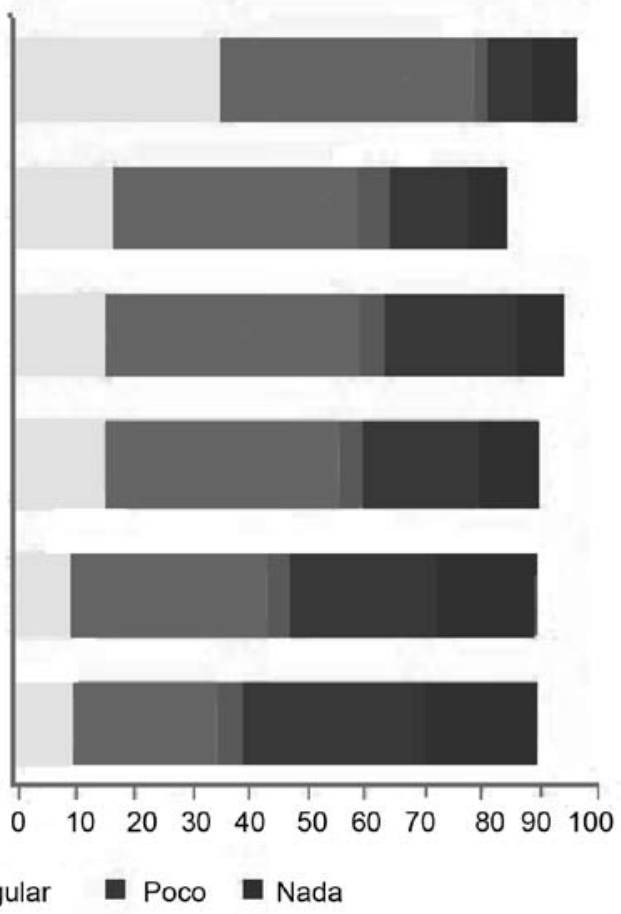

Con respecto a las condiciones laborales, más del $58 \%$ de los encuestados considera que los trabajadores públicos reciben un sueldo justo. En relación con el sistema de ingreso en la función pública, el $43 \%$ cree que es justo y garantiza la igualdad de oportunidades, mientras que un $41 \%$ opina lo contrario.

Sobre el grado de autonomía, un $78 \%$ cree que se debe garantizar el puesto de trabajo más allá de los cambios de gobierno (en contra, por tanto, del modelo spoil system). En cuanto a la participación de los funcionarios en la toma de decisiones, un 46,1\% de los entrevistados se muestran favorables y el $46,9 \%$ consideran que su tarea se limita a aplicar esas medidas.

Finalmente, con respecto a la magnitud del sector público, son mayoría quienes ponen en entredicho la afirmación de que «hay más funcionarios de los que hacen fal- 
ta» (el 49,6\% se muestra poco o nada de acuerdo), frente a los que la consideran cierta (34,6\%, que está muy o bastante de acuerdo con ella).

\section{El nuevo sistema normativo: un nuevo Estatuto de Autonomía de Cataluña (EAC) y el proyecto de Estatuto Básico del Empleado Público (EBEP)}

\subsection{El nuevo Estatuto de Autonomía de Cataluña}

La aprobación del nuevo Estatuto de Autonomía de Cataluña (EAC) y la más que probable aprobación del Estatuto Básico del Empleado Público (EBEP), actualmente en trámite en las Cortes españolas, supondrán la modificación de dos de los pilares fundamentales sobre los que descansa el marco normativo general de la función pública catalana. Este nuevo marco genera expectativas acerca de las posibilidades de ampliación de las facultades de autogobierno de la Generalitat en la materia.

En efecto, el artículo 136 del nuevo Estatuto de Autonomía establece textualmente lo siguiente:

Artículo 136. La función pública y el personal al servicio de las administraciones públicas catalanas

Corresponde a la Generalitat, en materia de función pública, respetando el principio de autonomía local:

a) La competencia exclusiva sobre el régimen estatutario del personal al servicio de las Administraciones públicas catalanas y sobre la ordenación y la organización de la función pública, con excepción de lo dispuesto en la letra b).

b) La competencia compartida para el desarrollo de los principios ordenadores del empleo público, sobre la adquisición y la pérdida de la condición de funcionario, las situaciones administrativas y los derechos, los deberes y las incompatibilidades del personal al servicio de las Administraciones públicas.

c) La competencia exclusiva, en materia de personal laboral, para la adaptación de la relación de puestos de trabajo a las necesidades derivadas de la organización administrativa y sobre la formación de este personal.

Este precepto se estructura en tres apartados, dos de los cuales, el $a$ ) y el $b$ ), interactúan para configurar una nueva delimitación competencial en materia de función pública, de forma que el contenido de la competencia exclusiva (apartado a) se concreta por excepción de lo que es objeto de la competencia compartida (apartado b).

Así, el apartado a) hace referencia a dos materias: 
- el régimen estatutario del personal al servicio de las administraciones catalanas;

- la ordenación y la organización de la función pública.

Mientras que el apartado $b$ ) concreta las submaterias derivadas de las dos anteriores, atribuyéndolas de forma compartida al Estado y la Generalitat. Son las siguientes:

- los principios ordenadores del empleo público;

- la adquisición y la pérdida de la condición de funcionario, las situaciones administrativas y los derechos, los deberes y las incompatibilidades del personal al servicio de las administraciones públicas.

\begin{tabular}{|c|c|c|c|}
\hline $\begin{array}{l}\text { Competencia } \\
\text { exclusiva } \\
\text { Generalitat } \\
\text { Artículo } 136 \\
\text { a) y c) }\end{array}$ & $\begin{array}{l}\text { Régimen estatutario } \\
\text { del personal al servicio } \\
\text { de las Administraciones } \\
\text { públicas catalanas }\end{array}$ & $\begin{array}{l}\text { Ordenación y } \\
\text { organización de } \\
\text { la función pública }\end{array}$ & $\begin{array}{l}\text { Adaptación } \\
\text { RLT } \\
\text { personal laboral } \\
\text { y formación } \\
\end{array}$ \\
\hline $\begin{array}{l}\text { Competencia } \\
\text { compartida } \\
\text { Artículo } 136 \text { b) }\end{array}$ & $\begin{array}{l}\text { - Adquisión y pérdida } \\
\text { de la condición de } \\
\text { funcionario } \\
\text { - Situaciones administrativas } \\
\text { - Derechos y deberes } \\
\text { - Incompatibilidades }\end{array}$ & $\begin{array}{l}\text { Desarrollo de } \\
\text { los principios } \\
\text { ordenadores }\end{array}$ & \\
\hline $\begin{array}{l}\text { Competencia } \\
\text { estatal }\end{array}$ & $\begin{array}{l}\text { Bases del régimen estatutario } \\
\text { funcionarios en las Administr } \\
\text { pública }(149.1 .18 \mathrm{CE})\end{array}$ & $\begin{array}{l}\text { le los } \\
\text { ciones }\end{array}$ & $\begin{array}{l}\text { Legislación } \\
\text { laboral } \\
\text { 149.1.7 CE }\end{array}$ \\
\hline
\end{tabular}

En consecuencia, la novedad que introduce el EAC de 2006 es que la determinación de los ámbitos materiales concretos y específicos que se integran dentro del concepto de régimen "estatutario del personal al servicio de las administraciones públicas» se realiza en la norma estatutaria y no directamente a través de la legislación básica estatal, o bien mediante la jurisprudencia constitucional, como había ocurrido hasta ahora.

En materia de función pública, esta concreción se materializa en el citado artículo 136, que retoma la definición dual del «régimen estatutario», al considerar que la relación «de servicio» (es decir, los derechos y deberes básicos, las condiciones de acceso 
y salida del sistema, las incompatibilidades y las situaciones administrativas, junto con los principios ordenadores) es lo que es objeto de competencia compartida con el Estado (y que, por tanto, puede ser desarrollado normativamente por parte de la Generalitat, en el marco de las bases que fije el Estado como principios o mínimo común normativo en normas con rango de ley), mientras que los restantes aspectos del régimen estatutario del personal al servicio de las administraciones catalanas y la ordenación y organización de la función pública son materias respecto a las cuales corresponde a la Generalitat, íntegra y exclusivamente, la potestad legislativa, reglamentaria y la función ejecutiva.

Es evidente que la redacción del artículo 136 del EAC de 2006 puede ser contradictoria con la jurisprudencia dictada hasta la fecha por el Tribunal Constitucional. No obstante, también es cierto que la aprobación del nuevo texto estatutario — que es, reiterémoslo, una norma estatal e integrante del bloque de la constitucionalidad- $y$, en particular, la definición que hace de los conceptos de "competencias exclusivas»y «compartidas» de los artículos 110 y 111, introducen un nuevo parámetro o canon para juzgar la constitucionalidad de la legislación estatal y autonómica que deberá ser tenido en cuenta necesariamente por el Tribunal Constitucional y que debe permitir dejar atrás unos planteamientos doctrinales hoy superados y habilitar las administraciones públicas territoriales para el desarrollo de modelos de función pública y de organización propios.

Competencia exclusiva (art. 110): corresponde a la GC, de manera íntegra, la competencia legislativa, la potestad reglamentaria y la función ejecutiva sobre la materia. Corresponde únicamente a la Generalitat el ejercicio de estas potestades y funciones.

\begin{tabular}{|c|c|c|}
\hline $\begin{array}{l}\text { Régimen estatutario del } \\
\text { personal de servicio de las } \\
\text { administraciones públicas } \\
\text { catalanas }\end{array}$ & $\begin{array}{l}\text { Ordenación y } \\
\text { organización de } \\
\text { la función pública }\end{array}$ & $\begin{array}{l}\text { Adaptación RTL } \\
\text { personal laboral } \\
\text { y formación }\end{array}$ \\
\hline & & \\
\hline $\begin{array}{l}\text { - Adquisición y pérdida } \\
\text { de la condición de funcionario } \\
\text { - Situaciones administrativas } \\
\text { - Derechos y deberes } \\
\text { - Incompatibilidades }\end{array}$ & $\begin{array}{l}\text { Desarrollo de los } \\
\text { principios } \\
\text { ordenadores }\end{array}$ & \\
\hline
\end{tabular}

Competencia compartida (art. 111): corresponde a la GC la potestad legislativa, la potestad reglamentaria y la función ejecutiva, en el marco de las bases que fije el estado como principios o mínimo común normativo en normas con rango de ley. 


\subsection{El proyecto de ley de Estatuto Básico del Empleado Público}

En este punto adquiere especial relevancia la elaboración del Estatuto Básico del Empleado Público (EBEP) por parte del Ministerio de Administraciones Públicas (MAP), es decir, la norma que debe contener las bases estatales de la función pública y que dejará sin efectos la Ley 30/1984, de 2 de agosto, de medidas para la reforma de la función pública, y gran parte de las normas singulares que regulan diferentes aspectos de la función pública. Como es obvio, el contenido definitivo del EBEP, con respecto a su ámbito de aplicación, a las materias que incluirá, a la intensidad con que las regule, etc., pueden condicionar el alcance de la reforma estatutaria a la que se ha hecho mención en apartados anteriores.

$\mathrm{Si}$ bien, en términos generales, se reduce considerablemente la extensión e intensidad de la regulación con carácter básico - en comparación con la legislación vigente-, hay un importante número de áreas donde la regulación continúa siendo excesiva y reglamentista (como el sistema retributivo o los sistemas de selección, entre otras) e, incluso, se añaden nuevos ámbitos materiales (como la regulación del personal directivo) y se consolidan otros de muy dudosa naturaleza básica (como la competencia para fijar los topes máximos de los incrementos retributivos anuales por ley de presupuestos generales del Estado).

No obstante, hay que señalar también que se introducen nuevos instrumentos para la mejora de la gestión de los recursos humanos (como la evaluación del desarrollo, la supeditación de la permanencia en lugares de concurso a la evaluación, la movilidad forzosa, la carrera profesional horizontal, etc.) de carácter innovador.

En cambio, rompiendo las expectativas de regular todo lo que abarca el concepto de «régimen estatutario», el proyecto no incluye la regulación de las incompatibilidades de los empleados públicos.

Analicemos seguidamente, de forma sintética, los aspectos más relevantes del EBEP y los puntos de fricción más importantes que pueden surgir con respecto al EAC de 2006 y su despliegue legislativo.

a) Ámbito de aplicación

Aun cuando en los primeros borradores del EBEP se regulaba conjuntamente al personal funcionario y al personal laboral, configurando así un nuevo concepto de «empleado público», la realidad es que el artículo 1 se ha dividido en dos párrafos, de tal manera que, con respecto a los funcionarios, se establece que la norma tiene por objeto regular «las bases del régimen estatutario» de los funcionarios públicos, mientras que, para el personal laboral, se establece que el EBEP «determina las normas aplica- 
bles». De hecho, a lo largo de toda la norma las remisiones a la legislación laboral y a los convenios que se establezcan son constantes.

Con respecto a las administraciones, hay que destacar la inclusión del personal al servicio de las administraciones de las entidades locales. En este sentido, se dispone de forma expresa que este personal se rige por el EBEP y por la legislación de las comunidades autónomas, siempre respetando la autonomía organizativa local.

b) Concepto y clases de empleados públicos

El EBEP añade a la definición clásica del personal funcionario (que refiere el nombramiento legal al principio de la carrera, la relación estatutaria y los servicios profesionales retribuidos) una aproximación al ejercicio de las funciones que le han sido reservadas. En este sentido, se señalan las que implican la participación directa o indirecta en el ejercicio de las potestades públicas o en la salvaguarda de los intereses generales del Estado y de las administraciones públicas, definición que, por su contenido indeterminado, deberá ser completada muy probablemente por la jurisprudencia, al igual que ha ocurrido con la regulación del acceso de los nacionales de la UE a la función pública de los estados miembros.

El EBEP incluye al personal directivo en la regulación del capítulo III, relativo a las distintas clases de empleados públicos, pero — de forma contradictoria - no lo incluye en la clasificación de empleados públicos. Su inclusión implica situar la función directiva bajo el ámbito material del régimen estatutario del personal al servicio de las administraciones públicas, pese a que es evidente que se trata de una materia de clara naturaleza organizativa.

Además, este precepto entra en colisión con el artículo 150 del EAC de 2006, que establece que corresponde a la Generalitat, en materia de organización de su administración, la competencia exclusiva sobre la regulación de los órganos y directivos públicos.

\section{c) Derechos y deberes}

En este título, se hallan regulados, en forma de derechos, algunos aspectos de la función pública que tienen un carácter claramente instrumental de la gestión de los recursos humanos, como son la carrera profesional, la promoción interna y la evaluación del desarrollo, las retribuciones, la jornada de trabajo, los permisos y las vacaciones.

d) Evaluación del desarrollo y carrera profesional

Aun cuando hay que valorar muy positivamente el establecimiento de la evaluación del desarrollo y de la carrera profesional, es preciso señalar también que, desde un punto de vista competencial, la fijación de los criterios a los que se deberán adecuar estos sistemas superan ampliamente el carácter de principios ordenadores o estándares mínimos que deben configurar un mínimo denominador común normativo. 


\section{e) Sistema retributivo}

Dentro del capítulo de derechos «retributivos» se incluye la sujeción del gasto en materia de personal a la Ley de Presupuestos del Estado, fundamentada en la competencia estatal para determinar las bases de la planificación de la actividad económica general, establecida en el artículo 149.1.13 CE. De este modo, los incrementos generales de retribuciones anuales de las administraciones públicas quedan sujetos a los topes que establezca la ley presupuestaria estatal. A nuestro entender, el EBEP no debería consagrar, a todos los efectos y permanente, lo que constituye una facultad estatal que puede ser ejercida de forma singularizada o no, cuando concurran las circunstancias que lo justifican, mediante la ley de presupuestos anual.

Asimismo, el proyecto de ley determina la estructura retributiva y sus conceptos con un grado de regulación muy reglamentista, impropio de una norma básica. Así, el texto regula con detalle las retribuciones básicas - determina los conceptos de sueldo y trienio- y establece que sus cuantías serán idénticas para todos los subgrupos profesionales de funcionarios de las diferentes administraciones públicas. En definitiva, la regulación del sistema retributivo es claramente excesiva, dado que hace imposible el desarrollo de modelos retributivos propios por parte de las diferentes administraciones públicas.

f) Sistemas de negociación colectiva, representación y participación

Es preciso destacar la creación de las mesas generales de negociación, que tratarán de las materias y condiciones generales de trabajo comunes al personal funcionario, estatutario y laboral de cada administración pública, y de la Mesa General de Negociación de las Administraciones Públicas, constituida por la Administración General del Estado (que la preside) y representantes de las comunidades autónomas y de la Federación Española de Municipios y Provincias (FEMP), con la vaga finalidad de tratar las materias negociables que deban ser reguladas mediante norma de carácter básico, así como "cualquier otra materia que, a todos los efectos, pueda, globalmente, afectar al personal de las administraciones públicas».

En segundo lugar, hay que destacar la ampliación de las materias que son objeto de negociación, entre las que se incluyen, por una parte, la planificación estratégica, cuando afecte a las condiciones de trabajo de los empleados públicos, y, por otra, las decisiones de las administraciones públicas que afecten a sus potestades de organización, cuando tengan repercusión sobre las condiciones de trabajo de los funcionarios públicos. Es muy dudoso que la planificación estratégica de los recursos humanos -así como de cualquier otra política pública - deba ser negociada, en la medida en que se trata de un instrumento inherente a las facultades de dirección y autoorganización de cualquier organización. Del mismo modo, las decisiones dictadas en uso de facultades autoorganizativas (como puede ser una reestructuración orgánica) que puedan tener 
repercusión sobre las condiciones de trabajo deberían quedar limitadas, como en la legislación vigente, al ámbito de la consulta a las organizaciones sindicales, no de la negociación.

g) Jornada de trabajo, permisos, licencias y vacaciones

Si bien se trata de una regulación de condiciones mínimas que, en algún supuesto, tiene más carácter supletorio que básico, no parece que la materia tenga la entidad suficiente como para formar parte del régimen estatutario básico de los funcionarios públicos de todas las administraciones públicas.

b) Selección del personal

En relación con este apartado, se recogen unos principios rectores relativos al acceso a la función pública (la publicidad de las convocatorias, la transparencia, la imparcialidad y profesionalidad de los miembros de los órganos de selección, etc.) que, junto con los requisitos para poder participar en las pruebas selectivas, deberán constituir la única normativa básica sobre esta materia. Es, por tanto, muy discutible que el EBEP pueda incorporar aspectos como los criterios para la composición de los órganos de selección, la exigencia de una norma con rango de ley para poder aplicar el sistema de concurso, la enumeración del tipo de pruebas que se podrán realizar (que puede ser interpretada como un numerus clausus), la especifica prohibición de declarar que ha superado los procesos selectivos un número superior de aspirantes que el de plazas convocadas, así como la oferta de empleo público como instrumento obligatorio de gestión de la provisión de las necesidades de personal, estableciendo el mandato de convocar los procesos selectivos para las vacantes convocadas y la necesidad de fijar el plazo máximo de convocatoria de los procesos selectivos.

i) Habilitación competencial

De acuerdo con la disposición final primera del anteproyecto, el EBEP se dicta al amparo del artículo 149.1.18 (régimen estatutario de los funcionarios de las administraciones públicas), del 149.1.7 (legislación laboral) y del 149.13 de la CE (bases y coordinación de la planificación general de la actividad económica).

Tras la aprobación del EAC de 2006, tal vez habría sido conveniente incluir en la disposición final del EBEP un reconocimiento y una salvaguarda de las competencias exclusivas que, en materia de función pública, tengan atribuidas las comunidades autónomas en sus respectivos estatutos de autonomía. La inclusión de este inciso supondría el reconocimiento y la visualización de la modificación que el EAC de 2006 introduce en «el bloque de la constitucionalidad», en la medida en que la competencia estatal para dictar las bases sobre una determinada materia ya no se infiere exclusivamente de los preceptos constitucionales, interpretados por el Estado de acuerdo con la jurisprudencia constitucional, sino que depende también de la delimitación competencial que establezcan los estatutos de autonomía. 


\subsection{Posibilidades que plantea el nuevo escenario}

El nuevo marco jurídico, teóricamente, amplía el techo competencial de la Generalitat en materia de función pública, por lo que respecta a su potestad legislativa, reglamentaria y de ejecución sobre el régimen estatutario de los funcionarios de las administraciones públicas catalanas y la ordenación y la organización de la función pública, sin más limitaciones que las derivadas de la determinación de unas submaterias respecto de los ámbitos materiales citados, sobre los que la Generalitat dispone de una competencia compartida y, por lo tanto, subordinada a las bases que establezca el Estado como principios o mínimo común normativo en normas con rango de ley.

No obstante, la regulación del EBEP incluye un conjunto de materias que pueden entrar en conflicto con las previsiones del EAC de 2006. Entre ellas se pueden citar la regulación del personal directivo, la subsistencia de regulaciones sectoriales para el personal docente y de los servicios de salud, así como los excesos en la regulación de aspectos que pertenecen al ámbito de la organización y la ordenación de la función pública, como los relativos a la evaluación del desarrollo, a la carrera profesional, al sistema retributivo, a los sistemas de selección, a la jornada, a los permisos y vacaciones, a la configuración de la negociación sindical, a la agrupación de los cuerpos y escalas en grupos y subgrupos, a la regulación de la escala de funcionarios autonómicos de habilitación nacional y a la habilitación competencial, por lo que respecta a la inclusión del título habilitador contenido en el artículo 149.1.13 de la CE y al hecho de que no se citan los estatutos de autonomía de las comunidades autónomas como normas delimitadoras de las competencias en materia de función pública.

En este contexto de incertidumbre resulta difícil y arriesgado plantear cuáles deben ser las actuaciones normativas que deben permitir configurar un modelo propio de función pública.

En primer lugar, hay que plantear la oportunidad de elaborar una ley marco del empleo público de Cataluña que regule los elementos esenciales organizativos y de régimen de prestación de servicios que permitan configurar un modelo propio de función pública susceptible de ser complementado o desarrollado normativamente, de acuerdo con los principios esenciales establecidos en la propia ley marco, para atender las especificidades de las diferentes administraciones públicas y los diversos ámbitos sectoriales de la función pública catalana.

Esta norma debería reunir buena parte de las materias que han sido objeto de un exhaustivo y completo análisis en el Libro Blanco de la Función Pública Catalana. Entre otros aspectos, deberían ser objeto de regulación las siguientes materias: 
1) La simplificación de las agrupaciones de funcionarios y la configuración de una planta organizativa común de cuerpos y escalas para todas las administraciones públicas catalanas.

2) Los criterios que deben regir la elección del régimen de prestación de servicios que mejor garantice la eficacia en la prestación de los servicios y que impida la aplicación de regímenes diferentes para el ejercicio de funciones idénticas.

3) Un tratamiento homogéneo del personal eventual.

4) Una estructuración de la clasificación de los funcionarios por titulación académica más simple.

5) La introducción de la gestión por competencias como modelo idóneo para la evaluación del desarrollo.

6) La creación del Comité de Valores Públicos de Cataluña para el impulso de la introducción de la infraestructura de la gestión de la ética en las administraciones públicas catalanas.

7) El desarrollo de instrumentos comunes de gestión del empleo público.

8) La creación de un modelo estándar de relación de puestos de trabajo y de plantillas de personal.

9) La implantación generalizada de registros de personal, de acuerdo con parámetros comunes que permitan su coordinación y, si procede, su utilización recíproca.

10) La creación del Observatorio del Empleo Público de Cataluña.

11) El establecimiento de un sistema de garantías extrajudicial.

12) La constitución de una mesa general única de las administraciones públicas catalanas.

13) La creación del Consejo Catalán del Empleo Público, como órgano integrado por todas las administraciones públicas catalanas con funciones de información, propuesta, consulta y ejecutivas con respecto al diseño y el establecimiento de la gestión de políticas de recursos humanos de Cataluña.

14) En materia de selección y provisión: entre otras, la posibilidad de tratar de forma integrada y conjunta las ofertas públicas de empleo; la creación de la Oficina Pública de Selección, organismo especializado y profesional que, por cuenta de las administraciones públicas catalanas y en representación de ellas, pueda llevar a cabo todos los procesos selectivos; el concurso general permanente como sistema ordinario de provisión de puestos de trabajo; la creación de la Oficina Pública de Provisión de Puestos de Trabajo de Cataluña.

15) El desarrollo de los criterios generales de la carrera profesional y del sistema retributivo, con la introducción de las retribuciones basadas en el desempeño del puesto de trabajo y en el logro de objetivos y resultados. 
Se trata de una norma de extrema complejidad técnica, dado que debe ser aplicable al personal de todas las administraciones públicas catalanas, con independencia de su régimen de vinculación (por lo tanto, funcionarios, laborales y personal estatutario), y al conjunto de sectores del servicio público. Esto hace, necesariamente, que deba adoptar la forma de ley marco y que sea preciso desarrollar cuerpos normativos complementarios o adecuar sus contenidos a las especificidades del personal de las diferentes administraciones públicas y de los diferentes sectores de prestación de servicios.

La adecuación a las diferentes realidades de las administraciones públicas catalanas, y en particular a los ámbitos sectoriales específicos, debería hacerse teniendo en cuenta, al menos, los colectivos de personal al servicio de la Administración de la Generalitat, incluido su sector público instrumental, el personal de las entidades locales y sus entes instrumentales, el personal docente no universitario, el personal que presta servicios en el sistema sanitario público, el personal de seguridad pública (Mossos d’Esquadra y policías locales), el personal de la Administración de Justicia, el personal de los servicios penitenciarios, el personal de administración y servicios de las universidades y el personal docente e investigador de las universidades.

Por otra parte, hay que recordar que el artículo 150 del EAC de 2006 establece que corresponde a la Generalitat, en materia de organización de su Administración, la competencia exclusiva sobre la estructura, la regulación de los órganos y directivos públicos, el funcionamiento y la articulación territorial, así como sobre las diversas modalidades organizativas e instrumentales para la actuación administrativa. Se atribuye, por tanto, la facultad de ordenar la dirección pública, que debería tener reflejo en un Estatuto del Directivo Público, sea como parte integrante de una nueva ley de organización de la Administración de la Generalitat, sea en una norma singular a través de la cual el Parlamento de Cataluña podría regular la función directiva de todas las administraciones públicas catalanas, con respeto al principio de autonomía local y universitaria.

Algunas de estas propuestas y de las incluidas en el Libro Blanco de la Función Pública Catalana quedaron recogidas en el documento programático «Entesa Nacional pel Progrès» del Gobierno de la Generalitat de Catalunya formado tras las elecciones de noviembre de 2006. Así, en materia de administración y función pública, el documento cita los objetivos de impulsar las reformas normativas necesarias para conseguir que la Generalitat cuente con una administración próxima y al servicio de la ciudadanía y establecer, a partir de la actividad institucional y las reformas normativas necesarias, un modelo de función pública fundamentado en los principios de servicio público y capaz de integrar a los mejores profesionales.

A estos efectos, el documento prevé un conjunto de actuaciones, como la definición - de acuerdo con el conjunto de administraciones y organismos públicos de Catalu- 
ña- y regulación de un sistema de función pública catalana que facilite la gestión de políticas y programas interadministrativos, que genere sinergias entre las distintas administraciones catalanas y que facilite la movilidad interadministrativa del personal.

Asimismo, se prevé la creación del Consejo Catalán del Empleo Público, con funciones de carácter consultivo, y del Observatorio del Empleo Público de Cataluña, así como la adopción de las medidas necesarias para que la legislación de empleo y función pública de Cataluña sean el instrumento fundamental para establecer un modelo de Administración pública que respete el principio de mérito, tenga en cuenta las competencias personales necesarias para desarrollar correctamente la función pública e instrumente procedimientos ágiles y transparentes.

Finalmente, se establece el compromiso de aprobar el Estatuto del Directivo Público con un sistema adecuado para su formación, promoción y reclutamiento basado en criterios de mérito y capacidad, dejando que cada administración defina los perfiles de su dirección pública. 